\title{
Energy strategies of industrial enterprises
}

\author{
L. D. Gitelman \& M. V. Kozhevnikov \\ Department of Energy and Industrial Management Systems, \\ Ural Federal University, Russia
}

\begin{abstract}
In the context of a common external instability, uncertainty and unpredictable dynamics of energy prices, energy management is becoming one of the key focuses in industrial activities. Especially it concerns energy-intensive industry consumers using expensive and qualified energy sources as well as operating in a competitive market environment. The paper describes the types and sequence of formation of energy policy based on the principles of rational market behaviour. A comparative analysis of energy strategies of industrial enterprises is given. The structure of energy market capacity of the company and its relationship with the process of implementation of the chosen energy strategy is revealed. The examples of organizational and technical solutions in the energy strategies that promote energy efficiency and environmentally friendly production are given.

Keywords: energy strategy, energy costs, energy market, rational behaviour, market potential, organizational risks.
\end{abstract}

\section{Introduction}

All too often, energy sector reforms are conducted without due attention to energy consumers, although from the point of view of public interests it is the consumer who should be the focus of reform. Among the problems that arise because of this, we can identify the following: information asymmetries and poor understanding of energy market structure, bounded rationality of consumers, unfair terms in standard contracts drafted by suppliers, lack of legislation and weak public awareness, low quality of supply and different services, including ecological, dispute resolution procedures. In the period immediately following liberalization especially information asymmetries and cognitive errors could be widespread [1, 2]. It must be noted also that electricity (and partly gas) are very peculiar goods 
for which we should not expect that all industrial consumers are able to make rational and informed choices.

Many corporate energy consumers are quite wary of current energy sector reforms and do not have a clear roadmap to adjust their behaviour to new circumstances. The following questions have to be answered:

- What are the implications of the reforms for the consumer?

- What will be the opportunities?

- What are the risks and threats?

- Is the consumer ready for operating in a competitive market environment?

Volatile energy prices have consistently increased the role of the energy factor in companies' economic performance. This is particularly relevant to energy intensive consumers that use energy derived from costly and renewable sources and operate in highly competitive markets.

\section{Key approaches to energy cost management}

There are two approaches to energy management which constitute an adequate response to growing energy prices [3]. The first one is to reduce energy costs of a company to a minimum considering more or less strict restrictions on the productivity of equipment, product quality, safety and the environmental impact of production processes. It has to be assumed that the consumer is unable to control energy prices or choose energy suppliers, so the desired result is mainly achieved through energy conservation and opting for cheaper energy sources when possible. In individual cases companies might adjust their range of products by discontinuing the ones with the highest energy inputs.

A peculiarity of this approach is that it weakens the link between energy management and operations management. As a result, the introduction of cuttingedge energy intensive technological processes and innovative products slows down, the availability of electric power per worker and electrification of production processes become stagnant. The approach, therefore, impedes the technological development of a company by keeping it at the achieved level of efficiency. This does not apply, however, to energy intensive facilities where electrification is at the maximum level. In this case, reducing costs is the only possible option.

The second approach is based on the principle of optimization of energy costs to meet the criteria of increasing the cost effectiveness of production and the company's competitiveness in relevant markets. In this case energy conservation and growing energy efficiency of production processes are combined with the introduction of new technologies and electrification, with energy saving measures and electrification not contradicting each other, but complementing and depending on one another. Although this concept might lead to higher energy costs than the first one, but technological development gets a new impetus to ensure the implementation of the company's strategic goals.

At the same time, execution of the more progressive and, of course, more effective concept of optimization of energy costs lies on the premise that the 
consumer is able to search for and freely choose between power supply options, energy prices, power suppliers and various supply services. As a result, a need appears to create an energy strategy of an industrial enterprise to be used as a tool for implementing the principle of "rational behaviour".

The management of manufacturing companies, therefore, starts to be guided by a completely new logic and methods when making managerial decisions. In the absence of any specific restrictions, such company can, for example, choose:

- whether to operate in a regulated or competitive electricity market;

- whether to buy electricity on the spot market or under a bilateral long-term contract;

- whether to enter the wholesale market or to sign a contract with a utility company on the retail market;

- whether to use the services of an independent utility company or a supplier of last resort;

- whether to deal with energy conservation issues on its own, or hire an energy service company;

- $\quad$ whether to buy electricity and heat from external suppliers or go off-grid;

- whether to use its privately generated electricity for the company purposes only, or to start selling it.

\section{Rational behaviour of the energy consumer}

Rational behaviour of the energy consumer can be defined as the desire to make the maximum use of advantages and opportunities offered by energy markets in order to cut energy costs, increase electrification of production facilities and develop one's own energy business while minimizing relevant threats and risks.

In this connection, a company should be guided by the following principles of rational behaviour.

Motivation for reducing (optimizing) energy costs. Different consumers will be inclined to take up a certain mode of behaviour in energy markets depending on the strength of their motivation to take active steps. Figure 1 shows two different kinds of behaviour: rational proactive (left) and passive ineffective (right). It has to be noted that positioning oneself in the market as a qualified consumer (who is an independent participant in the wholesale market), or as a customer of a utility is not necessarily a sign of the consumer's ineffective actions in the future (such positioning might be stipulated by technical characteristics of the consumer).

It is important to emphasize the impact of consumers' rational behaviour on boosting and maintaining competition in the production and sale of energy. By contrast, indifferent behaviour, if adopted en masse, can kill competition altogether.

Monitoring of one's energy market potential. Energy market potential describes technological, economic and organizational prerequisites for the consumer's ability to navigate a competitive market and manage market risks effectively. It is necessary to introduce energy market potential as a concept and a characteristic of an enterprise in order to determine: 
- $\quad$ the market status of the consumer;

- $\quad$ motivation for reducing energy costs and engaging in energy business;

- $\quad$ the readiness of energy managers to be proactive in markets;

- $\quad$ priority market strategies (considering the results of an earlier analysis).

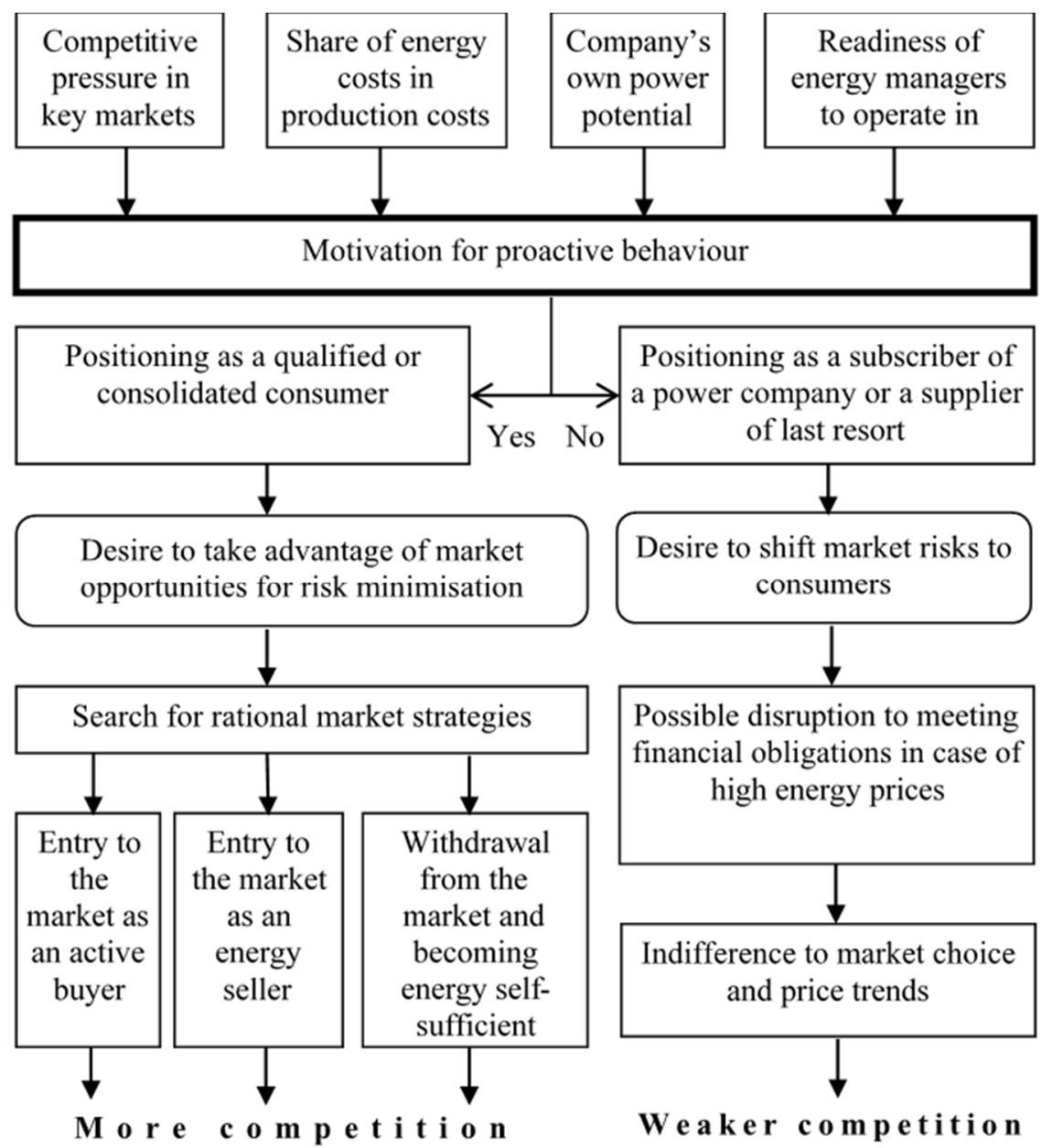

Figure 1: Alternative behaviours of industrial enterprises in electricity markets.

Table 1 presents elements of the potential, relevant indicators and areas of their application. Specifically, technological potential largely reflects the possibility of off-grid energy conservation, economic potential indicates the motivation factor; organizational potential shows the quality and preparedness of energy management in the company. The different types of energy potential call for different approaches to evaluating the characteristics. 
Table 1: Structure of energy potential of an industrial enterprise.

\begin{tabular}{|c|c|c|}
\hline $\begin{array}{c}\text { Type of } \\
\text { potential }\end{array}$ & $\begin{array}{l}\text { Indicators and } \\
\text { characteristics }\end{array}$ & Application \\
\hline \multirow[t]{5}{*}{ Technological } & Connected load & Determines the consumer's status \\
\hline & $\begin{array}{l}\text { Energy intensity of } \\
\text { production }\end{array}$ & $\begin{array}{l}\text { Shows the importance of energy } \\
\text { costs for core business }\end{array}$ \\
\hline & $\begin{array}{l}\text { Structure of energy } \\
\text { consumption }\end{array}$ & $\begin{array}{l}\text { Determines the choice of priority } \\
\text { sources of energy }\end{array}$ \\
\hline & Renewable energy potential & $\begin{array}{l}\text { Assesses the possibility of energy } \\
\text { self-sufficiency }\end{array}$ \\
\hline & $\begin{array}{l}\text { Adjustment options of } \\
\text { energy consumption units }\end{array}$ & $\begin{array}{l}\text { Indicates the expediency of } \\
\text { switching to peak-load pricing }\end{array}$ \\
\hline \multirow[t]{3}{*}{ Economic } & $\begin{array}{l}\text { Intensity of competition in } \\
\text { key markets }\end{array}$ & $\begin{array}{l}\text { Assesses motivation for reducing } \\
\text { energy costs }\end{array}$ \\
\hline & Investment opportunities & $\begin{array}{l}\text { Provides opportunity for off-the- } \\
\text { grid power supply; prospects of } \\
\text { developing energy business }\end{array}$ \\
\hline & Financial performance & Determines the consumer's status \\
\hline \multirow[t]{2}{*}{ Organizational } & $\begin{array}{l}\text { Availability of automated } \\
\text { metering devices }\end{array}$ & Determines the consumer's status \\
\hline & $\begin{array}{l}\text { Level of advancement in } \\
\text { organizational structure of } \\
\text { energy management } \\
\text { Capacity for (low-cost) } \\
\text { energy conservation }\end{array}$ & $\begin{array}{l}\text { ssesses the readiness of energy } \\
\text { management to operate in markets }\end{array}$ \\
\hline
\end{tabular}

It is possible to conclude that the higher the energy potential of a company, the bigger the room for active steps and the wider the choice of energy strategies and options of their combinations, while energy management becomes more flexible.

Flexible positioning in energy markets coupled with an active search for effective suppliers and bringing the company's energy management system into line with conditions in the competitive market. The principle implies that energy managers should possesses certain competencies to be able to operate successfully in electricity markets. Namely, they should be aware of:

- $\quad$ how electricity tariffs are constructed in the regulated and competitive sectors of the energy market;

- $\quad$ the basics of selecting an energy supplier;

- what services that are offered by energy service companies and utilities;

- how to organize cooperation with a vertically integrated company in a regulated market;

- $\quad$ modern methods of price risk management;

- technological and economic fundamentals of combined-cycle energy generation and ways of improving energy efficiency;

- $\quad$ the key types of advanced stand-alone power installations. 


\section{Building energy strategies of the company}

The main tool for implementing rational behaviour of the consumer in a certain sector of the market is his energy strategy. It defines a certain course of action that the company's energy management takes to take advantage of opportunities and offset threats and risks of the market.

Three basic strategies can be set out for different companies that reflect the above mentioned principles of rational behaviour in energy markets:

1) strategy of the buyer;

2) strategy of the seller;

3) combined strategy.

The strategies have a number of distinctive features.

Strategy of the buyer (Figure 2). This strategy can be referred to as a "price search strategy". It is suitable for companies that do not have power generating installations of their own and are not going to build any, or when available power generating units only meet part of their energy demand.

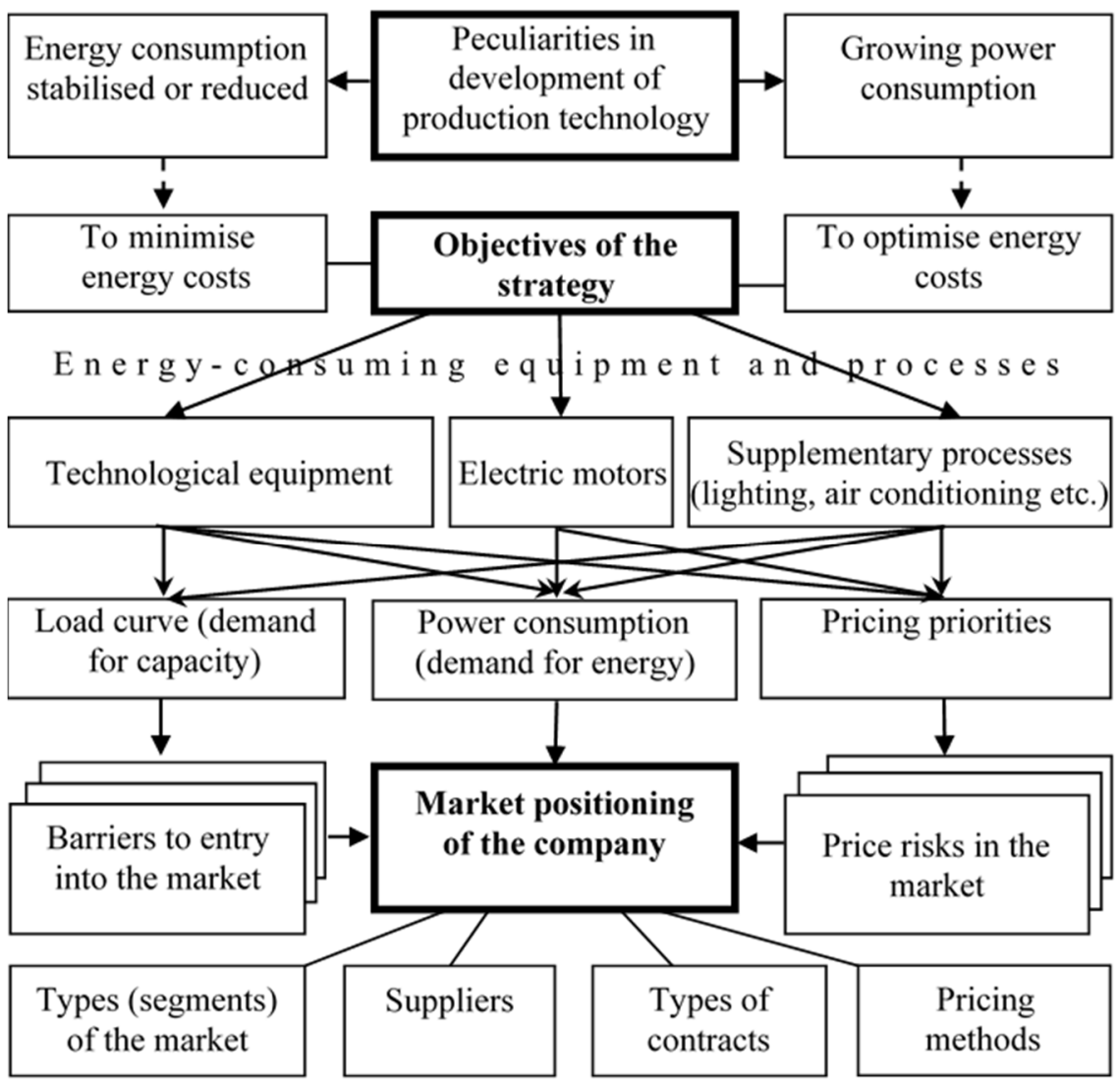

Figure 2: Building "price search" strategy of the buyer. 
Technology used by some industrial enterprises results in the high energy intensity of production and the degree of production electrification that is close to limit values (for example, in electrometallurgy). In such a case, the strategic goal would be to "minimise energy costs" by improving energy efficiency and encouraging energy conservation as well as selecting a certain acceptable price of electricity considering the technical and commercial reliability of suppliers. At the same time, the desire to obtain the lowest price while having a margin for efficiency improvement in areas of production where electricity has no alternative is not only unproductive because it in fact blocks up investment in rationalizing energy use in such facilities, but also confuses the mindset of managers.

Other companies have technical and economic capabilities to use interchangeable energy sources and increase the level of production electrification when replacing high-quality fuels with electricity (for example, in some high temperature processes in machine building). Making use of these opportunities naturally leads to a higher share of energy in total production costs. On the other hand, the cumulative effect of electrification brings down other types of costs, increases equipment productivity and the quality of products. The overall economic effectiveness of production grows.

This case is matched by an objective of the strategy defined as "optimisation of energy costs". Here, the search of the best price is aimed at increasing the economic competitiveness of electricity by comparison with a substituted energy source (mainly natural gas). This means that the upper threshold of the electricity price band is determined by prices of natural gas. Consequently, it makes sense here to look for the lowest possible price of electricity.

As shown in Figure 2, demand for electricity by a manufacturing company is broken down into three blocks combining specific consumers: energy consuming equipment and processes. The reason is that the objectives of the buyer's strategy might differ not only with regard to different companies, but also depending on energy consuming processes within a specific company, with pricing priorities being different too. For example, cost optimisation as a strategic objective is consistent with technological consumption where there is room for electrification (for example, furnaces can be fueled by either gas or electricity). That is why it is desirable to obtain a permanently low price of electricity here. The objective of cost minimisation covers electric machinery and lighting as electricity is virtually the only source of energy for them, so higher energy tariffs encourage conservation. Additionally, consumers in the indicated blocks differ in power consumption modes and, sometimes, in their requirements for reliability of supply.

Therefore, the "block method" suggested in the buyer's strategy makes it possible to make more informed plans for capacity and power demand and put forth differentiated requirements for price thresholds and price risks. For example, an acceptable price risk when purchasing electricity for lighting can be higher than for technological purposes. Naturally, the implementation of the approach will necessitate installing submeters on each piece of equipment.

Arranging demand in blocks of processes envisages that they can simultaneously bid in different energy markets with different price offering mechanisms and price risks. For this reason, it is necessary to regularly monitor 
prices in all potential markets and accumulate strategic information for more effective risk management.

Strategy of the seller (Figure 3). The strategy can be dubbed "energy business". The following processes are engineered as part of the strategy:

- $\quad$ generation and sale of electricity (capacity) in wholesale and retail markets;

- $\quad$ generation and sale of heat (capacity) in local markets;

- $\quad$ provision of technology services in a wholesale electric power market (under a contract with the grid operator).

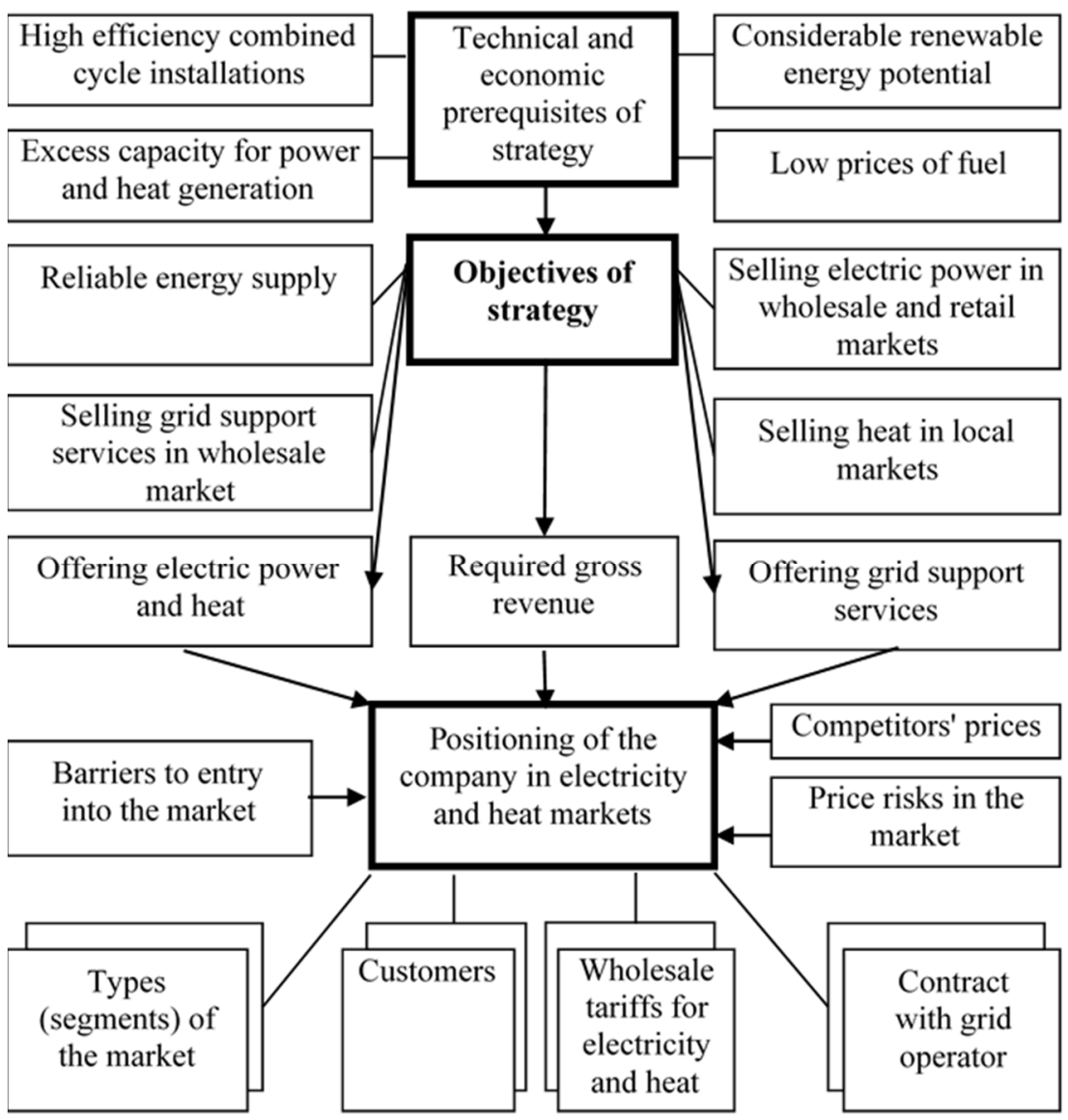

Figure 3: Building "energy business" strategy of the seller.

Running an energy business requires that the company have spare (excessive with regard to its own needs) generation capacity. The capacity can emerge as a result of reduction in its own energy consumption and subsequent changes in the output and product range. It can also emerge when industrial boilers are converted into steam turbine power plants and when factory steam turbine power plants are converted into gas turbine combined cycle plants. Both primary and backup 
installations can be used as commercial energy sources. Of course, only major corporations that have the necessary investment resources and access to cheap fossil fuel (e.g. big gas and oil producers) can afford to build heat and power plants with any significant capacity or buy assets of a major power plant for the purposes of energy business.

There are three main factors that define the competitiveness of an industrial heat and power plant in the heat and power market. First of all, it is the technological and economic characteristics of installations, steam turbine power and combined cycle units boasting the best ones. Secondly, it is the prices of fuel and the relative prices of electricity and natural gas. Taken together, these factors form the target revenue of the power plant. Thirdly, it is necessary to accurately determine wholesale tariff rates for electricity and heat, which will require effective price marketing arrangements and a method of allocation of the plant's indirect costs that is in line with the current market situation.

One has to bear in mind that the competitiveness of power plants varies seasonally: it is at the highest in the autumn and winter and is down in the summer when fossil fuelled electrical power generation decreases. It is, therefore, necessary to develop a mechanism of seasonal support for the company's energy business. Obviously, there are all sorts of solutions available.

As an ancillary business one should consider the potential of industrial heat and power plants to enter the market of technology (grid support) services (maintenance of grid reserve capacity, frequency regulation etc.). This market is organized by the grid operator, who also hires service providers.

Combined strategy (Figure 4). The strategy is called "consumer-regulator". Such a company buys electricity (capacity) in various markets, but also offers and provides frequency regulation services on the technology market. Two schemes can be employed as part of the strategy: with flexible power units and with back up peaking generators.

Flexible technological equipment should have the load shedding capability for peak demand times (up to a standstill) without any detrimental effect on the quality of products (for example, ferroalloy furnaces). During the nighttime the equipment should run in an accelerated mode. Demand for the regulatory resource of flexible technological equipment arises from the grid operator when, for example, it needs to restore balance of the grid or make up for a lack of peak demand capacity. In addition to receiving the asked price (later - a bid price set at auction) paid by the market operator for the services, the company can be exempt from a fee for grid reserve maintenance that is included in electricity tariff rates.

The standby peaking generator promptly goes online when the company's own costs of producing electricity fall below peak demand charges, and vice versa: when the company buys peak demand power if the prices are right, the generator is halted. This helps to manage through peak demand periods. Additionally, the generator can be included into the grid reserve capacity, which could enable the company to charge for this kind of service.

It has to be noted that any technology service available in the wholesale market is only paid for when it is solicited by the grid operator (provided there is an appropriate contract between the company and the market operator). 


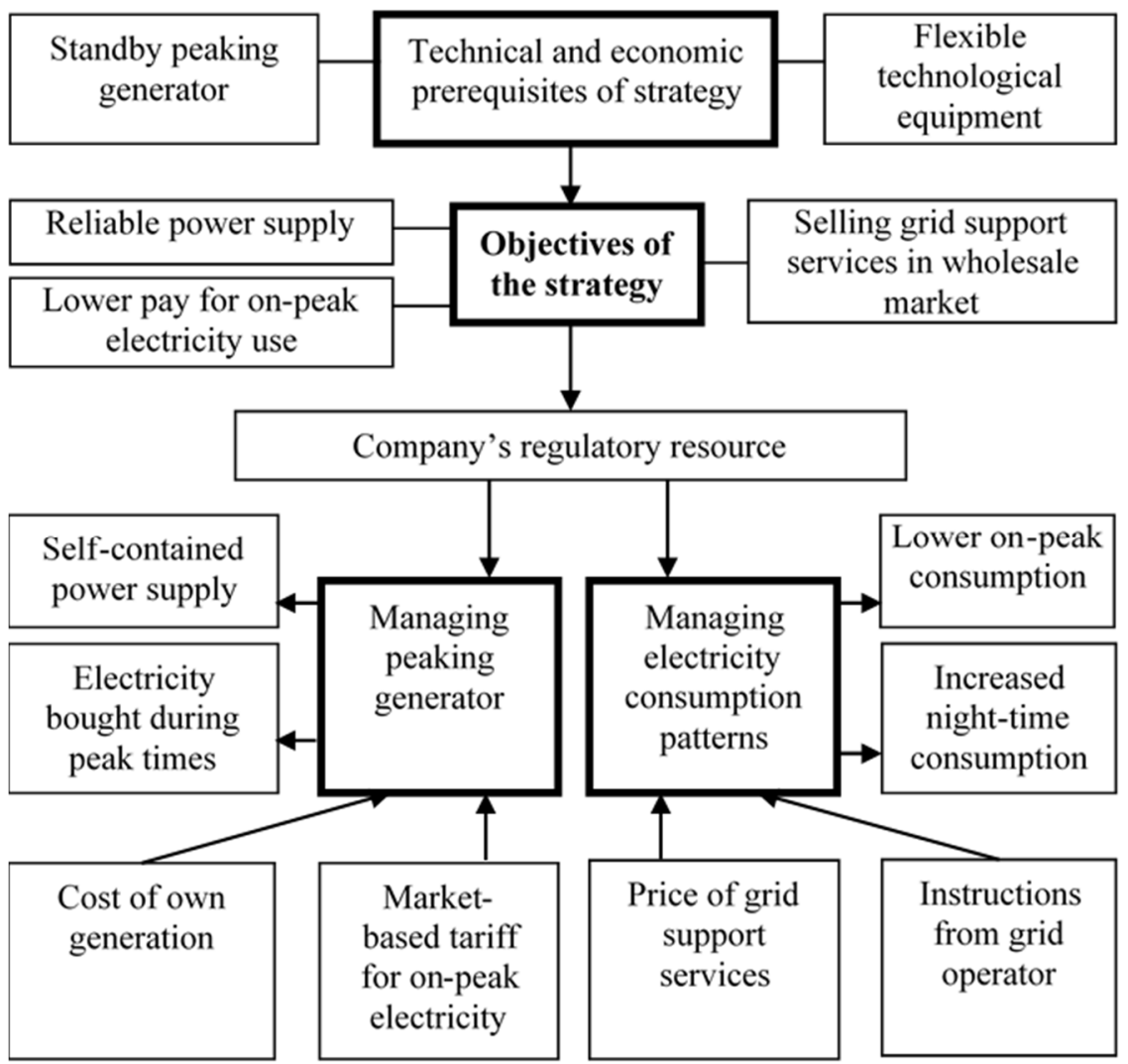

Figure 4: Building combined "consumer-regulator" strategy.

\section{Conclusion}

The following sequence of actions is suggested for building the above strategies:

- $\quad$ analyse technical and technological feature of production that predetermine the choice of a basic strategy;

- $\quad$ determine objectives, taking the technology factor into account;

- $\quad$ provide justification for the volume and structure of demand (supply) for energy sources and relevant services, including price priorities and restrictions;

- $\quad$ choose types (segments of markets), supplier (buyers), types of contracts and price-taking mechanisms.

We must emphasize that in terms of the consumers interests development of market relations in the power industry should ensure the stabilization and reduction of energy prices, increasing the quality and range of related services. Nevertheless, the basic value of the liberalized electricity market is the freedom of consumer choice. 


\section{References}

[1] Energy regulation and consumers' interests; Regional Technical Center of Research on European Consumption. http://papers.ssrn.com/sol3/ papers.cfm?abstract_id $=1120928$.

[2] Kozhevnikov, M.V., Approaches to the formation of energy service markets in developing countries. Proc. Of the 1st Int. Conf. On Energy Production and Management in the 21st Century: The Quest for Sustainable Energy, eds. C.A. Brebbia, E.R. Magaril \& M.Y. Khodorovsky, WIT Press: Southampton, pp. 27-34, 2014.

[3] Gitelman, L.D. \& Ratnikov, B.E., Energy Business, (in Russian), Economy: Moscow, 2013. 